\section{Exploring the work and competence of interactive researchers}

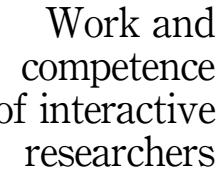

Peter E. Johansson

School of Innovation, Design and Engineering, Mälardalen University, Eskilstuna, Sweden, and

Andreas Wallo

Department of Behavioural Sciences and Learning, Linkopings Universitet, Linkoping, Sweden
Received 14 September 2018 Revised 15 April 2019 28 June 2019 19 August 2019 Accepted 17 October 2019

\begin{abstract}
Purpose - The purpose of this paper is to provide insight into the competence in use when working with interactive research, which is a continuation and elaboration of action research.

Design/methodology/approach - A qualitative research approach was adopted for the study. The main body of empirical material in this paper is based on two sources of data - a survey comprising open-ended questions, followed by a series of focus group interviews. The respondents were researchers with varying degrees of experience in using interactive research.

Findings - The findings provide illustrations of what characterises interactive research as work and identify an additional set of activities that go beyond traditional research activities. Some activities are relatively easy to describe, while others exist in the gaps between other activities - e.g. boundary spanning - and are harder to explicitly define in terms of implications for the involved researchers' competence. The work activities reaching beyond the traditional research boundaries are implicit and are not a common shared practice. From a competence point of view, this implies that the competence in use for these implicit tasks of interactive research becomes individually carried. Based on these findings, a number of individual aspects of what constitutes competence in use are suggested.

Research limitations/implications - In future studies, it would be valuable to use a mixed-method approach that also includes longitudinal observations of the actual work of conducting interactive research. Practical implications - The findings and suggestions for how to understand the competence of interactive researchers can be used as guidance for training in research education.

Originality/value - This study contributes to previous research by describing important requirements and critical elements of competence in use when conducting interactive research.

Keywords Competences, Action research, Methods

Paper type Research paper

\section{Introduction}

In the landscape of Scandinavian research, there is a strong tradition of utilising different kinds of collaborative research approaches when studying organisations (Ohlsson and Johansson, 2010). A common foundation of such approaches is that research is performed through close cooperation between researchers and stakeholders that are external to the academic context. In contrast to what can be labelled as more traditional research approaches, where external relations are used by the researcher as a means to gain access to adequate sets of data, collaborative research approaches value stakeholders outside of academia as important resources and co-creators in different types of research activities (Coghlan et al., 2012; Martin, 2010; Sannö, 2017; Van de Ven, 2007).
\end{abstract}

(C) Peter E. Johansson and Andreas Wallo. Published by Emerald Publishing Limited. This article is published under the Creative Commons Attribution (CC BY 4.0) licence. Anyone may reproduce, distribute, translate and create derivative works of this article (for both commercial \& non-commercial purposes), subject to full attribution to the original publication and authors. The full terms of this licence may be seen at http://creativecommons.org/licences/by/4.0/legalcode

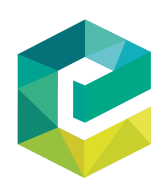

Journal of Manufacturing Technology Managemen Emerald Publishing Limited DOI 10.1108/JMTM-09-2018-0307 
The action research approach, developed by Lewin in the 1940s, is probably the most well-known type of collaborative research (Bradbury et al., 2008; Coughlan and Coghlan, 2002; Svensson and Aagaard Nielsen, 2006). However, some versions of action research have been criticised for prioritising practical development at the expense of long-term theory development (Dick, 2004, 2006; Seashore, 1976; Svensson, Ellström and Brulin, 2007; Yorks, 2005). Therefore, in this paper, the focus is on interactive research, which in recent years has emerged as an elaboration of the action research approach (Ohlsson and Johansson, 2010; Svensson, Ellström and Brulin, 2007). In interactive research, the importance of maintaining a division of labour between research and practice while continuing to build equal relationships between researchers and participants is clearly emphasised (Ellström, 2008). In comparison with the action research approach, interactive research focuses more on creating opportunities for researchers and practitioners to engage in joint learning and knowledge creation and less on the researcher's responsibility for solving practical problems in organisations.

Regardless of which approach to collaborative research is utilised, it is reasonable to believe that collaboration with actors outside of an academic context requires different sets of skills on the part of the involved researchers (Arieli et al., 2009; Snoeren et al., 2012). For instance, Mumford (2001) argues that having social skills is very important because such skills give the researcher a way of "getting in" and "staying in" the organisation, and similarly, Snoeren et al. (2012) contend that working with clients requires social competences to build and maintain trusting relationships. According to Westlander (2006), the role of an action researcher also implies a challenging balancing act between satisfying the needs of the client and simultaneously creating knowledge for critical discussions in the scientific community. In addition, Coughlan and Coghlan (2002) highlight that this type of research is often challenging because it requires the ability to cope with organisational changes occurring in real-time. The researcher must be skilled in different methods of inquiry, diagnosis and intervention but must also recognise that he or she is an instrument for generating data. To maintain validity, the researcher must, therefore, consciously subject their interpretations and assumptions to public scrutiny.

However, within the field of organisational studies in general and operations and innovation management in particular, there is still limited empirical evidence concerning how collaborative research is conducted in practice (Guertler et al., 2017), i.e. what we in this paper refer to as researchers' competence. Accordingly, the aim of the present paper is to provide insight into the competence in use when working with interactive research, and two research questions (RQ) are addressed. The first RQ is descriptive, and the second analytical:

$R Q 1$. What characterises the work of conducting interactive research?

$R Q 2$. What constitutes competence when performing interactive research?

Although this paper focuses on the interactive research approach, it will hopefully contribute to a more general discussion in the field of collaborative organisation research about what kind of work needs to be performed and in what context that work is embedded (Sandberg, 2000).

The remainder of the paper is structured as follows. First, the concept of interactive research is described and defined. Then, we present the theoretical framework that underpins the analysis as well as a review of previous studies on researchers' competences in interactive research. Next, the methodology employed in the study is presented, followed by a section that contains the findings of the empirical study, which are then analysed and discussed. Finally, the conclusions, limitations and implications of the paper are outlined.

\section{Defining interactive research}

Interactive research has been portrayed in a variety of ways, and in this paper, we will mainly draw on the interpretation put forth in the Nordic countries by Svensson and Aagaard Nielsen (2006) and Svensson, Eklund, Randle and Aronsson (2007). Svensson and Aagaard 
Nielsen (2006) argue that an interactive relationship between the researcher and the practitioner facilitates a more profound understanding of organisations and allows access to matters that would otherwise remain unseen. By integrating an insider and outsider perspective in a joint analysis, new knowledge with greater validity than knowledge produced through one-sided approaches can be created (Svensson, Eklund, Randle and Aronsson, 2007), and such knowledge usually has both higher scientific standards and greater practical relevance.

The complex relationship between the researcher and the practitioner has been illustrated as an interaction between two systems (Ellström et al., 1999; Svensson et al., 2015). On the one hand, there is the research system that is driven by researchers' typical activities, such as formulating research problems, designing empirical studies, collecting and analysing data, and developing conceptual frameworks and theories. On the other hand, there is the practice system, which is driven by more practical problem solving, the need for organisational development and the formulation of local theories (Ellström, 2008). In an interactive research project, these two systems are interconnected to form a joint cycle of collective learning where knowledge from both systems can create common conceptualisations and interpretations of the research phenomenon in question (Svensson, Eklund, Randle and Aronsson, 2007).

Although there are no manuals or guidelines that encompass how to conduct interactive research projects, as in most other research projects, three main phases can be identified: an initial phase, an implementation phase and a concluding phase (Sandberg and Wallo, 2013). The initial phase covers the actions taken before or at the beginning of a project, such as formulating the research problem, identifying the expected outcomes, assigning roles and designing empirical studies. During the implementation phase, a variety of activities are undertaken in both systems, e.g. data are collected, analysed and fed back to the partners, and change programmes might be launched by the organisations. As the project progresses, new discussions might be needed on research problems and about changes in the design of the studies (Burchert et al., 2014). In this way, the projects can be responsive both to what the preliminary results show and to needs or problems arising in participating organisations. In the concluding phase, the project is nearing its end-stage. When a project is completed, it is important to evaluate the results that have emerged and whether they have been put to use in the organisations (Sandberg and Wallo, 2013).

\section{Theory and key concepts}

This paper is underpinned by competence theory. While competence is a concept that appears difficult to pin down (Delamare Le Deist and Winterton, 2005; Eraut, 1998; Mulder et al., 2007), there are some tenets that recur in many of the most widespread definitions. First, an important distinction in this paper is made between competence in use and formal competence. Formal competence represents what the individual has documentation of (e.g. grades, certificates, diplomas, etc.), while competence in use refers to what the individual actually has the capacity to do and to the attributes of an employee that can be translated into a specific performance. The documentation of formal competence might not cover all of an individual's competence due to the implicit and tacit nature of competence in use (Ellström and Kock, 2008; Illeris, 2009; Martin et al., 2019; Warhurst and Thompson, 2006).

Second, competence is strongly associated with working life contexts and the abilities of professionals to perform their work and carry out certain tasks (Sandberg, 2000), that is, knowing what to do and how to do it in a given situation. Furthermore, work tasks should not be regarded in a narrow sense but rather as ranging from specific tasks to broader and more generic tasks (Hager and Gonczi, 1996). In this paper, competence will refer to the following definition (Ellström, 1997, p. 267):

[...] the potential capacity of an individual (or a collective) to successfully (according to certain formal or informal criteria, set by oneself or by somebody else) handle certain situations or complete a certain task or job.
Work and competence of interactive researchers 
Thus, to understand what makes some researchers better at performing interactive research, it is necessary to look at the competence in use of the researcher. According to Ellström (1992, 1997), competence in use is based on the following five types of components:

- $\quad$ perceptual motor skills (e.g. dexterity);

- cognitive factors (different types of knowledge and intellectual skills);

- affective factors (e.g. attitudes, values and motivations);

- personality traits (e.g. self-confidence); and

- social skills (e.g. communicative and cooperative skills).

Based on the identified components of competence, a taxonomy for describing and analysing occupational competence is suggested, even though in reality the different competences are closely intertwined (Ellström, 1992). The taxonomy comprises three main categories: task-oriented competence, ideological-normative competence and development-oriented competence. Task-oriented competence refers to the competence objectively needed to perform a designated task, in terms of both theoretically "knowing what" about things and practically "knowing how" to do things. As such, these tasks are directly related to the characteristics of the task and the methods used to carry out the task. Furthermore, task-oriented competence also includes the social skills needed in different situations. The ideological-normative competence represents a more general process-independent competence that is not directly related to any specific task, and it covers affective factors such as values, motivations and attitudes. Finally, development-oriented competence concerns the ability to innovate and develop the task itself or certain aspects of an organisation, targeting, for instance, quality, productivity or the work environment (Ellström, 1992).

A partly different, but complementary, explanation of how to understand competence at work is offered by Sandberg (2000) and Sandberg and Pinnington (2009). According to Sandberg, a reason why the same kind of work is performed in different ways and with different levels of quality is that the understanding and interpretation of work may vary, and as stated by Sandberg: "workers' knowledge, skills, and other attributes used in accomplishing work are preceded by and based upon their conceptions of work" (Sandberg, 2000 , p. 20). That is, competence in use is something more than the sum of an individual's knowledge and skills. Furthermore, in Sandberg and Pinnington (2009, p. 1162), the authors conclude that individual attributes - such as knowledge and skills - only constitute one aspect of competence, used to perform a certain work. Instead, competence in use emerges in any given situation as ways of being, based on the individual's self-understanding (e.g. identity as a researcher), his or her understanding of work, relations to other people and different tools that are accessible.

\section{Review of prior research on competence in interactive research}

To determine the state of research concerning competence requirements in interactive research, we reviewed the more recent research literature following the guidelines provided by Callahan $(2010,2014)$ and Torraco $(2005,2016)$. The inclusion criteria were as follows: research articles published in peer-reviewed journals, articles published during the period 1999-2019, and articles reporting research on the roles and competence requirements of interactive researchers. The literature search included combinations of the following keywords: "interactive research", "collaborative research", "competence", "competency", "skills" and "KSA (knowledge, skills and abilities/attitudes)". Scopus and Web of Science (WoS) were used for the search. 
The search in Scopus and WoS generated 506 articles after duplicates were removed. In addition, 17 articles were found by searching the following journals, i.e. "serendipitous findings" (Callahan, 2014, p. 273):

- Action Research;

- Action Research International;

- Educational Action Research;

- International Journal of Action Research;

- Science and Public Policy; and

- Qualitative Research.

In the next step, the titles and abstracts of the 523 articles were scanned based on the inclusion criteria of our study. Articles that did not focus on interactive research were excluded. Articles that were based on an interactive research approach but that did not discuss the roles or competencies of the researchers were also excluded from the review. After the initial scan, 63 articles were downloaded and underwent a thorough scan using the research methodology employed. This process further reduced the list of articles, making the total number of studies included in the literature review 29[1]. Notably, none of the articles explicitly used competence theory to discuss the interactive researcher, and only one article even mentioned the term "competence" (Krogh and Nielsen, 2017). Rather, it was more common that the roles and tasks of the researcher were discussed (e.g. Sandberg and Wallo, 2013; Svensson, Eklund, Randle and Aronsson, 2007), i.e. the articles mainly covered the qualification dimension of competence and paid less attention to what is required in terms of competence in use.

Each of the included articles was then carefully reviewed to identify the competence requirements placed on the researchers in the different phases of an interactive research project. Six broad themes emerged based on the inductive content analysis from the review:

- cooperate and establish trust;

- conceptualise and formulate research problems in collaboration;

- collect data and be sensitive to the field;

- analyse and disseminate;

- create opportunities for joint learning; and

- find a balance between research and practice and between closeness and distance.

Below, these six themes are presented and exemplified with findings from the reviewed articles. This section of the paper concludes with a more general critique of the previous studies.

\section{Theme 1: cooperate and establish trust}

The first theme concerns the importance of the researcher's ability to collaborate with other people. This might sound obvious and trivial, but in more traditional research, this is typically not a decisive factor, while in interactive research, it is considered a crucial capability (Svensson, Eklund, Randle and Aronsson, 2007). According to the studies, the most important aspect of this collaboration is to build trust and confidence in the relations among the practitioners early in the process (Rosenlund et al., 2015), both at high levels and at operative levels (Ahlström et al., 2007). Without trust, it becomes difficult to ensure commitment from external stakeholders and to gain entrance into the organisation (Ahlström et al., 2007; Krogh and Nielsen, 2017; Whitehurst and Richter, 2018). In many of the studies, the issue of power relations is highlighted as important to consider when building interactive relations.
Work and competence of interactive researchers 
For example, Gunnarsson (2007) points to the risk carried by the assumption that the researcher has some kind of interpretative privilege before the practitioner.

Furthermore, Sandberg and Wallo (2013) argue that it is also important that the researcher understands the power relationships between the different practitioners who are involved. The solution, according to the reviewed articles, is for both the researchers and practitioners to aspire to build inter-personal relations characterised by an exchange of views and experiences in a democratic dialogue that can develop new meaning and knowledge (Albinsson and Arnesson, 2010; Holmquist, 2009; Rosenlund et al., 2015; Svensson, 2007). A way to build a proper foundation for cooperation, trust and joint learning is to establish communicative spaces in which the researchers and practitioners reach an agreement concerning common goals and research questions that satisfy both the research and practice systems (Krogh and Nielsen, 2017; Sandberg and Wallo, 2013).

\section{Theme 2: conceptualise and formulate research problems in collaboration}

The second theme concerns the initial work of jointly identifying and designing common problems that can guide the research (Berglund et al., 2012; Holmquist, 2009). This work involves conceptualising the research concepts and problems and discussing potential research questions. According to previous studies, it is important for the researcher to ensure that different expectations of the research are brought up and analysed properly and that all conditions, such as time and resources, are discussed (Kelly and Moles, 2002; Svensson, Eklund, Randle and Aronsson, 2007). There is also a need to establish a mutual understanding concerning the means of reaching the end of the process and to discuss what the goals of the process are and how they should be achieved (Sandberg and Wallo, 2013). According to Krogh and Nielsen (2017), it is especially important for the researcher to communicate and explain the research ideas in a succinct manner to ensure that the practitioners can see the benefits of being part of the process and to ascribe meaning to the research project. In this regard, participation in the conceptualisation of the research problem can be a factor that creates both commitments from practitioners (Calder, 2004; Krogh and Nielsen, 2017) and more relevant research questions for the researchers (Holmquist, 2009).

In this process, it is also important that each party gains insights into each other's realities (Albinsson and Arnesson, 2010; Gunnarsson, 2007; Johannisson, 2018). Ahlström et al. (2007) also note that the plan itself might not be the most important outcome; rather, the common understanding that planning can create might be most important. Another important part of the conceptualisation and formulation of research problems is to discuss ethical issues and take them into consideration (Åkerström and Brunnberg, 2013; Nyström et al., 2018).

\section{Theme 3: collect data and be sensitive to the field}

Concerning the third theme, data collection, there are no guidelines for an interactive researcher (Svensson, Eklund, Randle and Aronsson, 2007). Rather, in all the reviewed studies that included empirical material, the methods used were quite conventional. However, a recurring pattern in the articles was that a qualitative methodology was typically preferred (cf. Berglund et al., 2012; Johannisson, 2018; Gustavsson, 2009). There were also some studies with a mixed-methods design (Eklund and Karltun, 2012; Gensby et al., 2018; Holmquist, 2009; Rosenlund et al., 2015; Svensson, 2007), but no study was based only on quantitative data analysis.

What distinguishes interactive research in terms of data collection is that the researcher needs to have more than one string on his/her bow. The research problem, which determines the choice of method, might be elaborated or revised during the research process (Ahlström et al., 2007), thus creating an openness for other methods, or the research might need to 
alternate between methods that allow for close examinations and methods with a more overarching focus (Albinsson and Arnesson, 2010). The researcher must thereby be flexible and have the ability to shift between different roles (Albinsson and Arnesson, 2017; Berglund et al., 2012; Eklund and Karltun, 2012; Rosenlund, 2017). Furthermore, interactive research is considered more labour-intensive and time consuming than traditional research (Nyström et al., 2018; Svensson, Eklund, Randle and Aronsson, 2007). For instance, Whitehurst and Richter (2018) argue that it takes a considerable time for researchers to build relationships with external stakeholders required to secure those stakeholders' engagement and commitment to the research. Other distinguishing factors are that practitioners can participate in the development of data collection tools (Âkerström and Brunnberg, 2013) and that it is important to document the process carefully so that it can be made available and inspire other researchers and practitioners (Svensson, Eklund, Randle and Aronsson, 2007).

\section{Theme 4: analyse and disseminate}

Theme 4 addresses how the collected data are analysed and disseminated. Typically, it is the task of the researcher to arrange good opportunities for joint analysis together with participating practitioners (Akerström and Brunnberg, 2013). According to the articles, the researcher's role is to not only arrange the opportunity for analysis but also act as a facilitator during the analytical work (Rosenlund and Rosell, 2017). Akerström and Brunnberg (2013) also highlight that before the analysis, the researcher has a job to do with the practitioners in terms of sorting data. Svensson, Eklund, Randle and Aronsson (2007) argue that the joint analysis allows researchers to try different interpretations, and Rosenlund and Rosell (2017) highlight the possibility of joint dialogue seminars to validate the research findings. Sandberg and Wallo (2013) identified three types of seminars for analysis that they call the stirring-up seminar, the supporting seminar and the steering seminar. In a stirring-up seminar, issues of power can be presented and critically discussed. In a supporting seminar, the focus is on enhancing the understanding of a difficult issue for the practice system. In a steering seminar, the presentation of research can be combined with guided discussions that follow a carefully planned agenda.

Van der Haar et al. (2013) argue that joint analysis involves a complex role for the researcher in terms of organisation and participation, and consideration must be given to contradictory knowledge claims because there are people who might want to direct the outcome of research in a certain direction. Van der Haar et al. suggest that the researcher needs a reflexive attitude to understand what influence researchers and practitioners have on the research. As far as the dissemination of research results are concerned, most studies appear to have focussed on traditional methods, such as the publication of scientific texts and presentations at conferences (e.g. Ahlström et al., 2007). There are, however, examples of studies in which dissemination has involved practitioners. Svensson, Eklund, Randle and Aronsson (2007) produced a book together with the practitioners, and in the study by Åkerström and Brunnberg (2013), the practitioners wrote a short report that was edited by the researchers.

\section{Theme 5: create opportunities for joint learning}

The fifth theme addresses the importance of creating opportunities for joint learning and the development of new knowledge throughout the entire research process (Johannisson, 2018; Svensson, Eklund, Randle and Aronsson, 2007). This is one of the most important tasks in interactive research but perhaps also one of the most difficult to accomplish. What is evident in the articles is that there are no rules or guidelines to follow. However, there are two recurring patterns. The first pattern is that the researcher should have the ability to actively support learning (Nyström et al., 2018), for example, by creating training
Work and competence of interactive researchers 
courses (Seim et al., 2014) or making contributions to ongoing in-house training programmes (Watson, 2000). Other ways of supporting learning include contributing new perspectives (Holmquist, 2009), serving as a sounding board, or problematising different issues to promote reflection and new lines of thinking (Albinsson, 2015). In addition, several studies highlight the need to educate practitioners in interactive research as a methodology as well as in specific methods of data collection and analysis and in theoretical models and concepts (Albinsson and Arnesson, 2017; Eklund and Karltun, 2012; Åkerström and Brunnberg, 2013).

The second pattern is that the researcher needs to be able to create arenas dedicated to learning, i.e. a kind of "third context" where theory and practice can meet (Holmquist, 2007). The most common approach is that the researcher arranges different types of seminars, workshops, conferences or meetings for this purpose (Albinsson and Arnesson, 2010; Berglund et al., 2012; Gensby et al., 2018; Gustavsson, 2009; Kelly and Moles, 2002; Rosenlund, 2017; Rosenlund and Rosell, 2017). In these cases, a joint analysis as described under theme 4 is usually carried out.

Theme 6: find a balance between research and practice and between closeness and distance The sixth and last theme might present the greatest difficulty for the interactive researcher and concerns balancing the different demands and expectations of different stakeholders (Holmquist, 2009). It is possible to distinguish two patterns in the articles: the balance between the research system and the practice system and the balance between proximity and distance to practice. With regard to the balance between research and practice, several authors raise the point of having a division of labour in so far as the researcher is responsible for driving the search for new knowledge and the development of new theories, while practitioners are responsible for the actual development that takes place in the organisations (Eklund and Karltun, 2012; Krogh and Nielsen, 2017; Sandberg and Wallo, 2013). However, finding the balance between these two systems is not an easy task (Eklund and Karltun, 2012), and in the reviewed studies, it is not possible to fully deduce how this has been accomplished. The main concern appears to be that interactive research should not be considered invalid by the scientific community (Whitehurst and Richter, 2018), which is why the need to comply with the rules required by scientific rigour is emphasised and why the findings and new knowledge are presented in classical academic contexts such as seminars and conferences. Krogh and Nielsen (2017) note that it might be a good idea to establish advisory boards that meet outside the immediate research process.

Regarding the balance between proximity and distance, a central issue concerns the ability to be critical of the occurrences being studied that the researcher is also part of creating. Two main arguments can be discerned. First, proximity should not be too great because the researcher will lose the opportunity to present criticisms (Albinsson and Arnesson, 2010; Gensby et al., 2018). Here, warnings are issued for researchers not to "go native" (Svensson, Eklund, Randle and Aronsson, 2007) or to be "co-opted" by practice (Van der Haar et al., 2013). Second, proximity might provide opportunities for relevant criticism that can be accepted by practitioners because such criticism is perceived to come from within the organisation (Svensson, 2007; Watson, 2000). However, the difficulty with this position is that there is a great deal of openness, courage and trust required on the part of both the researcher and the participants (Svensson, 2007) and that the researcher cannot become "one of the gang" (Svensson, Eklund, Randle and Aronsson, 2007). Interestingly, none of the articles seem to have an answer for where to draw the line for when the researcher gets too close. A possible solution is to alternate the degrees of proximity and distance during different periods of a research project (Albinsson, 2015). Læssøe et al. (2013) highlight the concept of a "critical friend" as a way to explain to practitioners what role the researcher's critique can play in an interactive project. 
According to Læssøe et al., a true friend is not someone who always agrees with you but rather someone who dares to criticise you and challenge your notions about yourself and your situation. In summary, there are some comprehensive conclusions that can be drawn from the review of previous research. It is not surprising that the articles that provide the most information about roles and competencies are conceptual and theoretically driven. Here, however, it is worth noting that these texts comprise quite a few normative elements and attempts to establish a "canon" in the field. The articles that instead mainly aim at presenting and discussing results created by using interactive research are usually poorly developed in a methodological sense and rarely advance the field forward. In some cases, interactive research appears more like a label that is applied to the research, and the interactive elements are not clearly elaborated in the text. This can, of course, also be a result of the inherent limitations of the article format regarding possibilities for a detailed description of the methodology used.

Furthermore, most of the studies come from the Scandinavian countries, with a clear dominance of studies from Sweden. It is also most common for the studies to be based on a variation of interactive research developed in Sweden. Authors such as Lennart Svensson and Per-Erik Ellström are referred to by all articles except one. However, in that article (Van der Haar et al., 2013), there is no reference to the interactive methodology at all. In terms of academic subjects and disciplines, the review presented here shows that behavioural sciences such as pedagogy and sociology are the most common. Interestingly, there is only one study that can be labelled operations management (Berglund et al., 2012).

\section{Methods}

To address the research questions and to gain knowledge of the competence in use when performing interactive research, a sequential mixed-method approach (Merriam and Tisdell, 2015) was adopted. This approach was chosen due to the challenges of capturing the competence used to perform work in a specific context, in this case when planning and conducting interactive research. The main body of empirical material in this paper is based on two sources of data - a survey comprising open-ended questions, followed by a series of focus group interviews. First, the survey was conducted within one university, and as a second step, the responses from the survey were used to design the forthcoming series of focus group interviews. In total, the empirical material contains the voices of 38 researchers with varying degrees of experience in using interactive research.

\section{The survey}

To gain insights into how interactive researchers frame what constitutes challenges as well as success criteria when conducting and planning interactive research, a survey was conducted. The survey was distributed online to senior researchers and $\mathrm{PhD}$ students at a university of applied sciences in Sweden and, more specifically, researchers with a background in operations and/or innovation management research. All respondents had some experience working with collaborative or interactive research approaches, especially working closely with partners in the manufacturing industry. What makes this university interesting for this specific study is that for many years, it has promoted a collaborative research approach called "co-production" as a strategic initiative. In total, 27 researchers responded to the survey, including 17 senior researchers and $10 \mathrm{PhD}$ students. In the findings section below, all respondents are referred to as "researchers".

The survey included a battery of 14 questions, including both closed and open-ended questions. In this paper, however, it is mainly the responses to the following two open-ended questions (referred to as the survey) that have been used.

Q1. What do you experience as the major challenges with regard to planning and conducting a research project in collaboration with stakeholders outside academia?

\section{Work and competence of interactive researchers}


Q2. Based on your own experiences, what are the primary criteria to successfully plan and conduct a research project in collaboration with stakeholders outside academia?

Based on the 27 responses to each of the two questions, the survey generated 1,300 words of written answers.

\section{Focus group interviews}

In addition to the survey responses, three focus group interviews (referred to below as the interviews) were conducted with researchers from three different Swedish universities. A focus group is a research technique that collects data through group-based interaction on a topic selected by the researcher and where the researcher takes an active role in creating the group discussion (Morgan, 1996). The first focus group was composed of one of the authors, two senior researchers and one $\mathrm{PhD}$ candidate. The second focus group was composed of one of the authors and three senior researchers, and finally, the third focus group was composed of one of the authors and two senior researchers. In total, in addition to the authors, nine researchers participated in the focus groups. All the participants - including the authors of the present article - had experience conducting interactive research projects and had also published journal articles and/or book chapters on interactive research; they had also been the organisers of conferences and workshops on the topic. Furthermore, several of the respondents are represented in national and/or international associations and boards promoting interactive research or related research approaches (e.g. Participatory Action Research).

The focus group interviews were semi-structured and covered three principal themes: prerequisites for conducting interactive research in practice, critical tasks in conducting interactive research, and development of competence to conduct interactive research. Each theme was discussed, and a number of follow-up questions were addressed based on the responses. The respondents were also encouraged to further elaborate their answers and build on each other's responses. The interviews lasted between 1 and $1.5 \mathrm{~h}$ and were later fully transcribed.

\section{Analysis}

By using two different sets of data sources - the focus group interviews and the survey - we were able to achieve data triangulation (Denzin and Lincoln, 2011). The data analysis was conducted in two steps. In the first step, an inductive content analysis was conducted (Miles et al., 2019), which resulted in the clustering of 170 statements into approximately 80 different categories. To better understand the competence of interactive research, the categories were analysed based on the overall intentions of interactive research, the approach in research, and the activities and tasks conducted in practice.

Eight main themes emerged during the analysis, including five representing "Overall intentions and approaches in research" and three representing "Work activities". In the second step, these themes were used to further organise the empirical material. Within each identified theme, we searched for tensions that allowed us to explore the qualities of the phenomena that were identified. In the findings section, quotations from the interviews and the survey are presented. In the third step, to position the themes in the context of competence, the identified themes were analysed from a competence perspective and compared with the themes that were identified in the literature review.

\section{Findings}

In this section, the answers to $R Q 1$ - What characterises the work of conducting interactive research? - are provided, based on the analysis of the interviews and the survey. 
Overall intentions and approaches in research

Drawing on the responses, the work of interactive research entails a range of critical aspects that need to be considered by the researchers. Below follows an account of themes that show the overall intentions and approaches in research and some critical aspects that have been identified.

The character of interactive research as work - multiple stakeholders, multiple goals. What characterises interactive research as work is the interplay among multiple stakeholders, which also means that multiple goals and ambitions need to be considered when planning and conducting the research. To begin, a key condition is that there is a genuine willingness from all participants to collaborate and to be open to new perspectives:

There must also be a willingness to discuss the issues at large for companies, if we say that it is a company you work with, which has a picture of what the problem is, and they have to somehow open up to new perspectives. The same also goes for the researchers who also need to be willing to open up and listen to what might be present in this problem. (Interview 2)

Consequently, what is highlighted in the empirical material is the importance of identifying problems or questions that are of interest to both researchers and practitioners. However, it is also argued by several respondents in the survey and the interviews that the stakeholders' practical problems should precede the research; that is, the research problems should ideally be well situated in the stakeholders' daily activities or in large on-going change processes. In the survey, one respondent mentioned that a condition for success is that there must be an "openness and respect for both worlds", and a second respondent stressed the importance of an "understanding of different stakeholders' motives and interests and each stakeholder's role in the project". Furthermore, the word "mutual" was frequently used to signal that the research should be relevant from both an academic and a practical standpoint.

To achieve these dual goals, the research design needs to be adaptable, and in one of the interviews, the research design was described as something that emerges. The design thus turns out to be something other than initially intended. Later in the interview, however, a concern was raised concerning the problem of too much openness in the research process, and instead a stepwise model was suggested:

You need to have some kind of window and a stepwise model, like in construction projects where the construction researchers claim that you can't have full participation at all times, and instead you have to decide that now we are doing things like this, and then the window is closed. Then you open the window again, and it can be open for a while, and then you close it again. Then you move on. (Interview 1)

Although the overall intentions of interactive research were agreed upon by the respondents, the degree of interaction varied, and there was no common view of how to design interactive research.

Multiple goals - a source of inadequacy and uncritical research. The overall goal of contributing to each stakeholder's needs and finding a balance between academic and practical needs does not seem to come easily, and the dualities of interactive research sometimes seem to be insurmountable. Some critical voices emerged, indicating that there are dilemmas that need to be considered when working on interactive research projects.

Lack of time is one of the most frequently cited dilemmas. In addition to the fact that for most organisations, it is challenging to allocate time to non-core activities, interactive research was described as being "time-consuming". The respondents argued that activities such as "gaining access to companies/stakeholders" and "coordinating research activities" take considerable time. Therefore, it is not the data collection that takes the most time but rather the surrounding activities, and the activities that the researchers have committed to as a part of the project are commonly more than just "doing research":

You need to stay in touch all the time. The data collection in itself [...] can almost be more efficient than when doing traditional research, due to you already having an engagement, the doors are
Work and competence of interactive researchers 
open, and you don't have to spend so much time on that. But then you have things like feedback, analysing seminars, and reporting. (Interview 1)

Furthermore, the dual demands of publishing research in high-impact journals on the one hand and contributing to the utilisation of research in the partner organisation on the other are experienced negatively by the researchers, as these demands tend to create a sense of inadequacy.

A second dilemma occurs when the external stakeholders' interests dominate and the research risks losing its critical stance. Thus, when there is a strong urge to satisfy the companies, this might increase the likelihood of being uncritical in order to avoid offending the partners. This caution for the stakeholders can, in turn, be related to situations where the researchers are the driving force of an interactive research project, which makes the researchers dependent on the partners' engagement. Although the ambition is that the interactive research is based on mutual interest and shared responsibilities, there are no equal or mutual relations because the researchers are more dependent on the practitioners to obtain access to the data than the other way around.

"As imagined and as done" - Pseudo-interactive research. Despite having ideas of what constitutes good practice in interactive research, a major challenge seems to be the discrepancy between what is intended in terms of doing interactive research and how it is done in practice. This discrepancy is referred to by one of the respondents in interview 1 as "interactive research as imagined and interactive research as done". That is, the research might be intended as interactive, but in reality, it becomes "the same old procedure" as in traditional research.

There are likely many explanations for this discrepancy, but one that was given in the interviews concerned the Swedish context wherein several funding agencies require collaboration with external stakeholders to fund a research project. This requirement creates a situation where it can be beneficial to use labels such as "interactive research", but this label is really just an excuse to get access to funding or empirical data. The same respondent later refers to research that is not based on an actual interest in gaining new knowledge about shared problems as "pseudo-interactive research". A similar view is also expressed by another respondent:

Sometimes we label things as co-production, things that I would say aren't co-production. I would instead call it traditional research simply because you go out and collect [data] [...] and you interview people. But this is not co-production. Co-production is when you do something together. (Interview 2)

This pseudo-interactivity or lack of genuine interest in collaborating can also be true from an external stakeholder perspective. For example, when a company is part of a project due to kindness or due to partnership agreements, or when a researcher has convinced practitioners to participate who actually have a low interest in participating.

Independence and dependence of inter-personal relations. Establishing and maintaining strong relations is described as one of the essential aspects of success in interactive research. In the material, the need for both independence of and dependence on inter-personal relations can be identified, which at first glance seems counterintuitive. However, independence and dependence work at different levels - independence at the institutional level and dependence at the individual level.

One basic element of interactive research is described as long-term relations in which external stakeholders participate in research planning and activities. To support long-term relations, contracts and partnership agreements between the collaborating partners are used to overcome a too-strong reliance on single researchers and to sustain relations over time. The institutional relations are also described as lowering the threshold for collaboration 
and as serving as a door opener. Less "footwork" is needed when such relations have been worked out beforehand.

The partnership agreements then serve as a foundation from which it is easier to access and initiate collaborations. However, several of the respondents emphasised that interactive research cannot solely rely on institutional relations; such research is also highly dependent on strong inter-personal relations between the participating researchers and practitioners:

However, the actual work doesn't take place on that level [institutional relations] [...] It might make it easier for us to get access, and there can be a commitment from the management that makes it easier to get in. But the requirements for actually doing interactive work are also about us coming along with the individual to whom we are referred. (Interview 3)

Thus, inter-personal relations are emphasised as a key to creating and maintaining trust between the participating individuals and the knowledge that exists in established relations. The issue of trust is also held as central to accessing the "real problems" of external stakeholders. Consequently, this increases the requirements for what the interactive researcher needs in terms knowledge, skills and abilities, and to be good at building inter-personal relations requires "Good human knowledge, the ability to listen empathically [...], knowledge in how to negotiate and establish relations".

\section{Work activities in interactive research - implicit and individually carried out}

In the empirical material, traditional research activities - such as conducting interviews or surveys - were described as important parts of what characterises interactive research. However, the respondents also emphasised a number of other activities that are critical when conducting interactive research, including activities that perhaps are more or less implicit and therefore not always addressed through planning or education.

"Party planning" and project management. Apart from planning the research design, interactive research is characterised by activities such as project management and coordination of work between the participating stakeholders. In the early phases, a large part of the work is about finding the right participants and then getting the stakeholders engaged and involved in the planning of the research. The project management activities that occur during a project are described in interview 3 as "party planning". That is, nurturing the social relations with partners to create longstanding bonds and trust:

You have to plan for informal and formal meetings, communication. Yes, everything, the whole project. Everything that cannot be published, or which does not qualify [you as a researcher]. (Interview 3)

Conducting a research project with a duration of two to three years, plus an additional year of planning the research before the project has been granted funding, makes it challenging to maintain continuity in the project. In addition, factors such as changed priorities at the companies or key personnel who are learning about their jobs do not make it any easier. Nevertheless, the activities that are intended to keep the stakeholders engaged and committed to the project must be on-going throughout the whole process.

Shared goals and co-creation of knowledge in dialogues. In all three interviews as well as in the survey, "dialogue" was frequently referred to as a key activity of interactive research. Dialogue is an activity embedded in other activities and can take place in different settings; however, when described by the respondents, it was mainly linked to the ambition to achieve the objectives of creating shared goals and the co-creation of knowledge:

To me it is important what is happening in the dialogue, and that you actually meet and discuss. Because this is necessary to find a common ground about the problem that you actually would like to address together. And it may take time before you get there, because it is about changing 
perspectives and experiences to find a problem that in a way has two dimensions - being practically relevant and scientifically relevant. (Interview 2)

Furthermore, in interview 2, a distinction is made between "creating knowledge" and "disseminating knowledge". The former is described to be at the core of interactive research:

We are talking about two things really. It is about generating knowledge, and it is about disseminating knowledge, and I believe co-production is more about generating knowledge. For the disseminating part, I hand over the responsibility to the organisation and the company to take this on, what has been learned in co-production. (Interview 2)

This standpoint is further emphasised as one of the respondents argues that new knowledge is created in the interaction between project participants, where all partners bring their knowledge or skills into the collaboration.

Boundary spanning - transgressing dual contexts. A recurring theme in the empirical material is that the interactive researcher needs to be grounded in dual contexts and must fit into both the academic and the industrial settings. Thus, interactive research requires boundary spanners, as one of the respondents described them. First, at the core of boundary-spanning activities is that the interactive researcher understands the stakeholders' context, and in the ideal situation, this understanding is bilateral.

That is, that I understand what knowledge I need to be able to conduct research in collaboration with a partner. But the partner also needs to understand that even though we are working at a University, we have certain knowledge about what's going on in the field. (Survey)

By having a range of experiences from different sectors, it is easier to cross the boundaries between different organisations. This is further illustrated by one of the respondents in interview 1 who stated that understanding industrial processes as well as processes in the public sector contributes to readiness to interact with and engage in different stakeholders' realities.

Second, boundary-spanning requires the ability to adapt language to fit the specific context, for example, avoiding academic jargon when interacting with companies and understanding the company "language" and using it to frame the research. However, the switch between languages seems to be easier said than done. One respondent, also in interview 1, stressed the difficulties of writing for different audiences - practitioners and researchers - and of adjusting to the situation with a suitable message.

Third, in the process of doing interactive research, tensions might arise because there are opposing thoughts regarding what constitutes valid knowledge or when the empirical data reveal things that are perhaps uncomfortable for the external stakeholders. Boundary spanning, then, also implies being able to navigate through the tensions that emerge during a project and in the midst of each stakeholder's goals and ambitions.

The interactive researcher, a self-made workshop facilitator. According to the respondents, a key part of interactive research projects as work are workshops, where researchers and project partners meet and work together. The workshops were described as having many different functions, e.g. to inspire, to enable the sharing of experiences, to perform data collection or to provide feedback on tentative findings:

Then, you have a workshop where you discuss and try to identify what has happened in a specific situation, and then you try to convert it into written text. To me, a large portion of co-production occurs when you together try to understand what has happened and what was going on. (Interview 3)

In the best of cases, one of the respondents argued, workshops are planned in close collaboration with the project partners. However, this is another example of activities that take time and are difficult to accomplish. 
Against the background where the importance of workshops is highlighted, it seems somewhat paradoxical that the overall experience among the respondents is that there is limited sharing - or no sharing at all - among colleagues regarding best practices for planning and conducting workshops. Instead, each researcher/project invents their own way of doing workshops based on their own conceptions about what to achieve and how to plan and execute it:

But, in my view you [as an interactive researcher] are very much left alone to find out "what best practices are" [...] Everybody is using workshops, but we don't share between projects how we are doing great workshops. Or how we are running great meetings to enable useful data collection, and at the same time provide feedback. In a way there is almost an ad hoc development, if you are lucky you are working with the right persons who have the right skills. (Interview 3)

This creates a situation where the quality of the workshops becomes a function of researchers' self-organised learning experiences because there is little systematic training in how to manage or run workshops. Instead, the ability to run workshops is described as learned by participating and running workshops, compared to other methods that are used during the research - such as interviews, observations and surveys - which have a given place in research education.

Hence, the development of competence in conducting different critical elements of interactive research relies heavily on the researcher's experience-based learning. There are plenty of statements indicating that researchers put great effort into finding the best way of conducting interactive research. Moreover, there are few examples of a developed praxis for sharing details between colleagues, and there is little focus on how researchers are actually conducting different work activities or solving tasks. The interviews indicate that more joint reflection is desired.

\section{Discussion}

The aim of the present paper is to provide insights into the competence in use when performing interactive research. In the previous section, the first RQ was addressed, and in this section, the second $\mathrm{RQ}$ - What constitutes competence when performing interactive research? - is addressed, followed by an overall discussion of researchers' competence in performing interactive research. Due to the definitions of competence used in this paper (Ellström, 1997; Sandberg, 2000), there are challenges in how to empirically capture the competence in use when performing work. However, by analysing the respondents' experiences of the overall intentions of using interactive research, their approach to research, and the type of work activities and tasks undertaken when conducting interactive research, it is possible to say something about the individual aspects of competence in interactive research.

There are many similarities when comparing the inductively generated themes from prior research and the themes from the empirical analysis presented here. That is, there are similar descriptions of overall intentions and outputs, e.g. "Create opportunities for joint learning" (Holmquist, 2007, 2009; Johannisson, 2018) or "Cooperate and establish trust practitioners" (Ahlström et al., 2007; Rosenlund et al., 2015). One possible explanation for these similarities is that the overall intentions and approaches in interactive research are collectively shared and stem from similar sources in the Scandinavian research community (cf. Svensson, Ellström and Brulin, 2007).

However, when looking at interactive research as work, prior research includes few detailed descriptions of the practice of interactive research, except what can be labelled as traditional research work, e.g. collecting or analysing data (Berglund et al., 2012; Eklund and Karltun, 2012). Moreover, even fewer descriptions of how to successfully conduct the identified task are provided. Instead, activities and tasks are identified and included in brief role descriptions (Albinsson and Arnesson, 2017; Rosenlund and Rosell, 2017) that do not

\section{Work and competence of interactive researchers}


provide any deeper understanding of researchers' competence in use. Hence, the competence of the interactive researcher is a neglected aspect in prior research on interactive research.

The findings in the present paper, thus, contribute by providing illustrations of an additional set of work activities that go beyond traditional research activities and of how traditional research activities are re-contextualised due to a different understanding of the research work from an interactive research standpoint. Some of the activities that researchers carry out are relatively easy to explain and describe - e.g. project management - while other activities are placed in the gaps between other activities - e.g. boundary spanning - and are harder to explicitly define in terms of implications for the involved researchers' competence. It is, therefore, reasonable to believe that the work of conducting interactive research that reaches outside of the traditional research boundaries is mainly individually carried and is not a common shared practice in the research community.

Hence, critical elements of researchers' competence in use (Ellström, 1997) to conduct interactive research is not explicated or codified in such ways that it becomes easy to overlook when defining what constitutes key elements of interactive research competence. Several scholars have emphasised social skills as a key to creating trust and equal relationships between participating stakeholders in collaborative research (Sandberg and Wallo, 2013; Snoeren et al., 2012; Svensson, Eklund, Randle and Aronsson, 2007). In the words of Mumford (2001), social skills become the key to "getting in" and "staying in" the organisations. However, a conclusion drawn in this paper is that trust in inter-personal relations is only one of many necessary aspects of ensuring good quality in interactive research. Competence in interactive research - in addition to more conventional research tasks - means having the capacity to deal with an additional set of critical tasks that interactive research entails. However, competence also encompasses the capacity to reconsider traditional research activities to align with the goals and intentions of interactive research and thus avoid turning them into various bottlenecks when conducting interactive research. Based on Ellström's taxonomy (1992) and the findings presented in this paper, we suggest a number of individual aspects of what is required in terms of competence (Table I).

By applying the taxonomy in Table I to the findings, it is possible to explain what causes poor performance in interactive research. For example, the "pseudo interactive research" that is referred to in the findings can be seen as an expression of limited knowledge concerning how to coordinate collaborative activities or a lack of ability to manage the dual aims of research and practical development initiatives.

However, by looking at the findings from the perspective of Sandberg and Pinnington (2009), it can be argued that the conduct of interactive research is also conditioned by the researchers' self-understanding and understanding of work. That is, poor performance in interactive research is not necessarily bound to a lack of a certain set of knowledge and skills; it can also be a question of one's identity as a researcher. The "pseudo-interactive research" can then also be an expression of a different set of values guiding the work and thus what is identified as critical aspects of that work.

\section{Practical implications}

When looking at what it takes to carry out successful interactive research, a conclusion is that interactive research is demanding and requires a very versatile researcher or team of researchers. Because critical elements of competence in interactive research to a high degree are individually carried and not explicitly shared, learning and development of competence are first and foremost a result of learning from the practice of conducting interactive research, as is well illustrated in the findings. This observation raises questions of how to train researchers in such a way that the neglected aspects of competence are addressed. Thus, the lack of clear descriptions of what characterises interactive research as 
I.

II.

III.
Task-oriented competence

Knowing what ...

the state-of-art in research is

appropriate research methods are available

the context of participating organizations is

Knowing how to ...

coordinate collaborative activities

organize different kinds of meetings and workshops

use and adapt appropriate research methods

create communicative spaces

Cooperation and communication skills to ...

establish and maintain trust in inter-personal relations

negotiate and establish agreements

communicate and educate

adapt use of language to fit practice

Ideological-normative competence

Having a profound understanding of the potential value of practitioners' contributions

Being ...

committed to the norms and attitudes of the research society

extraverted, adaptive, open-minded, agreeable, critical, meticulous

Development-oriented competence

Having the ability to ...

translate research output into practical development initiatives

translate practically related issues into research problems

develop new theories and concepts
Table I.

A tentative taxonomy of competence in interactive research

work and an undeveloped understanding of the competence of interactive researchers is likely to make research education become arbitrary with regard to training researchers and developing their competence. On this note, this paper contributes to previous research by describing important characteristics and critical elements of the competence needed when conducting interactive research. A practical implication is that the identified aspects of competence can be used as guidance for training and formulating curricular activities in research education.

\section{Limitations and future research}

A limitation of the outcomes in the present paper is that the analysis relied on relatively few written and oral statements about the respondents' previous experiences. In future studies, it would be valuable to use a mixed-method approach that also includes longitudinal observations of the actual work of conducting interactive research. Such an approach would most likely enable capturing other dimensions of competence in use (Ellström, 1997). Further, it would be of value to include the practitioners' perspectives on what constitutes critical elements of researchers' competence, but also, to explore what constitutes critical elements of practitioners' competence to conduct interactive research. For example, the practitioner's competence likely influences the interplay between researchers and practitioners and how the task of planning and conducting interactive research unfolds in practice. A hypothesis is that the gap between the researchers and the industrial partners' level of competence to conduct interactive research is a potential bottleneck because it affects the conditions for mutually identifying problems and co-creating knowledge.

\section{Note}

1. The selected articles are marked with * in the reference list. 


\section{References}

The articles marked with * were included in the literature review.

*Ahlström, P., Nilsson, F. and Olve, N.G. (2007), "Mobilising and nurturing collaboration in research - the value of a focused imagination", International Journal of Action Research, Vol. 3 No. 3, pp. 297-323.

*Åkerström, J. and Brunnberg, E. (2013), "Young people as partners in research: experiences from an interactive research circle with adolescent girls", Qualitative Research, Vol. 13 No. 5, pp. 528-545.

*Albinsson, G. (2015), "Development-oriented learning in a project team: applying an interactive research approach", International Journal of Action Research, Vol. 11 No. 3, pp. 289-316.

*Albinsson, G. and Arnesson, K. (2010), "How critical can you be as an on-going evaluator?", International Journal of Action Research, Vol. 6 Nos 2-3, pp. 256-287.

*Albinsson, G. and Arnesson, K. (2017), "Dialogue in a learning process: problematization of gender and gender equality in higher education”, Reflective Practice, Vol. 18 No. 4, pp. 474-495.

Arieli, D., Friedman, V.J. and Agbaria, K. (2009), "The paradox of participation in action research", Action Research, Vol. 7 No. 3, pp. 263-290.

*Berglund, M., Harlin, U., Gustavsson, M. and Säfsten, K. (2012), "New ways of organizing product introductions", Work, Vol. 41 No. S1, pp. 4856-4861.

Bradbury, H., Mirvis, P., Neilsen, E. and Pasmore, W. (2008), "Action research at work: creating the future following the path from Lewin", in Reason, P. and Bradbury, H. (Eds), The SAGE Handbook of Action Research: Participative Inquiry and Practice, SAGE, London, pp. 77-92.

Burchert, J., Hoeve, A. and Kämäräinen, P. (2014), "Interactive research on innovations in vocational education and training (VET): lessons from Dutch and German cases", International Journal for Research in Vocational Education and Training (IJRVET), Vol. 1 No. 2, pp. 143-160.

*Calder, I. (2004), "Forests and water - closing the gap between public and science perceptions", Water Science and Technology, Vol. 49 No. 7, pp. 39-53.

Callahan, J.L. (2010), "Constructing a manuscript: distinguishing integrative literature reviews and conceptual and theory articles", Human Resource Development Review, Vol. 9 No. 3, pp. 300-304.

Callahan, J.L. (2014), "Writing literature reviews: a reprise and update", Human Resource Development Review, Vol. 13 No. 3, pp. 271-275.

Coghlan, D., Cirella, S. and Shani, A.B. (2012), "Action research and collaborative management research: more than meets the eye?", International Journal of Action Research, Vol. 8 No. 1, pp. $45-67$.

Coughlan, P. and Coghlan, D. (2002), "Action research for operations management”, International Journal of Operations and Production Management, Vol. 22 No. 2, pp. 220-240.

Delamare Le Deist, F. and Winterton, J. (2005), “What is competence?”, Human Resource Development International, Vol. 8 No. 1, pp. 27-46.

Denzin, N.K. and Lincoln, Y.S. (2011), The Sage Handbook of Qualitative Research, Sage, Thousand Oaks, CA.

Dick, B. (2004), “Action research literature. Themes and trends", Action Research, Vol. 2 No. 4, pp. $425-444$.

Dick, B. (2006), “Action research literature 2004-2006. Themes and trends”, Action Research, Vol. 4 No. 4, pp. 439-458.

*Eklund, J. and Karltun, J. (2012), “Ten years of experience from interactive ergonomics projects”, Work, Vol. 41 No. S1, pp. 4862-4865.

Ellström, P.-E. (1992), Kompetens, utbildning och lärande i arbetslivet: Problem, begrepp och teoretiska perspektiv, Publica, Stockholm.

Ellström, P.-E. (1997), "The many meanings of occupational competence and qualification”, Journal of European Industrial Training, Vol. 21 Nos 6/7, pp. 266-273. 
Ellström, P.E. (2008), "Knowledge creation through interactive research: a learning approach", paper presented at the ECER Conference, Gothenburg, 10-12 September.

Ellström, P.-E. and Kock, H. (2008), "Competence development in the workplace: concepts strategies and effects", Asia Pacific Education Review, Vol. 9 No. 1, pp. 5-20.

Ellström, P.-E., Eklund, J., Kock, H., Lindström, L. and Melin, U. (1999), Knowledge Creation Through Collaborative Research: An Emerging Model, CMTO, Linköping University, Linköping.

Eraut, M. (1998), “Concepts of competence”, Journal of Interprofessional Care, Vol. 12 No. 2, pp. 127-139.

*Gensby, U., Braathen, T.N., Jensen, C. and Eftedal, M. (2018), "Designing a process evaluation to examine mechanisms of change in return to work outcomes following participation in occupational rehabilitation: a theory-driven and interactive research approach", International Journal of Disability Management, Vol. 13 No. 1, pp. 1-16, doi: 10.1017/idm.2018.2.

Guertler, M.R., Kriz, A., McGregor, C., Bankins, S. and Bucolo, S. (2017), “'And Action!' - Rigour meets relevance in Action Innovation Management (AIM)", paper presented at the XXVIII ISPIM Innovation Conference, Vienna, 18-21 June.

*Gunnarsson, E. (2007), "Other sides of the coin: a feminist perspective on robustness in science and knowledge production”, International Journal of Action Research, Vol. 3 No. 3, pp. 349-363.

*Gustavsson, M. (2009), "Facilitating expansive learning in a public sector organization", Studies in Continuing Education, Vol. 31 No. 3, pp. 245-259.

Hager, P. and Gonczi, A. (1996), "What is competence?”, Medical Teacher, Vol. 18 No. 1, pp. 15-18.

*Holmquist, M. (2007), "Managing project transformation in a complex context", Creativity and Innovation Management, Vol. 16 No. 1, pp. 46-52.

*Holmquist, M. (2009), "Interactive research and joint learning for practical contributions", Journal of Workplace Learning, Vol. 21 No. 3, pp. 240-251.

Illeris, K.., (2009), "Competence, learning and education. How can competences be learned and how can they be developed in formal education?", in Illeris, K. (Ed), International Perspectives on Competence Development. Developing Skills and Capabilities, Routledge, London, pp. 93-108.

*Johannisson, B. (2018), "Disclosing everyday practices constituting social entrepreneuring -a case of necessity effectuation", Entrepreneurship and Regional Development, Vol. 30 Nos 3-4, pp. 390-406.

*Kelly, R. and Moles, R. (2002), "The development of local agenda 21 in the Mid-west region of Ireland: a case study in interactive research and indicator development", Journal of Environmental Planning and Management, Vol. 45 No. 6, pp. 889-912.

*Krogh, A.H. and Nielsen, M.V. (2017), "Succeeding with interactive research: how to manage research with and about society", Research for All, Vol. 1 No. 2, pp. 351-364.

*Læssøe, J., Feinstein, N.W. and Blum, N. (2013), "Environmental education policy research-challenges and ways research might cope with them", Environmental Education Research, Vol. 19 No. 2, pp. 231-242.

Martin, J., Elg, M., Gremyr, I. and Wallo, A. (2019), "Towards a quality management competence framework: exploring needed competencies in quality management", Total Quality Management \& Business Excellence, pp. 1-20, doi: 10.1080/14783363.2019.1576516.

Martin, S. (2010), "Co-production of social research: strategies for engaged scholarship", Public Money \& Management, Vol. 30 No. 4, pp. 211-218.

Merriam, S. and Tisdell, E. (2015), Qualitative Research. A Guide to Design and Implementation, John Wiley \& Sons, San Francisco, CA.

Miles, M., Huberman, M. and Saldana, J. (2019), Qualitative Data Analysis: A Methods Sourcebook, SAGE Publications, Thousand Oaks, CA.

Morgan, D.L. (1996), "Focus groups", Annual Review of Sociology, Vol. 22 No. 1, pp. 129-152.

Mulder, M., Weigel, T. and Collins, K. (2007), "The concept of competence in the development of vocational education and training in selected EU member states: a critical analysis", Journal of Vocational Education \& Training, Vol. 59 No. 1, pp. 67-88. 
Mumford, E. (2001), "Advice for an action researcher", Information Technology and People, Vol. 14 No. 1, pp. 12-27.

*Nyström, M.E., Karltun, J., Keller, C. and Andersson Gäre, B. (2018), "Collaborative and partnership research for improvement of health and social services: researcher's experiences from 20 projects", Health Research Policy and Systems, Vol. 16 No. 1, pp. 1-17, doi: 10.1186/s12961-018-0322-0.

Ohlsson, J. and Johansson, P. (2010), "Interactive research as a strategy for practice-based learning: designing competence development and professional growth in local school practice", in Billett, S. (Ed.), Learning Through Practice. Models, Traditions, Orientations and Approaches, Springer International, Dordrecht, Heidelberg, London, New York, NY, pp. 240-255.

*Rosenlund, J. (2017), "Improving regional waste management using the circular economy as an epistemic object", Environmental Sociology, Vol. 3 No. 3, pp. 297-307.

*Rosenlund, J. and Rosell, E. (2017), "Using dialogue arenas to manage boundaries between sectors and disciplines in environmental research projects", International Journal of Action Research, Vol. 13 No. 1, pp. 24-38.

*Rosenlund, J., Hogland, W., Johansson, A.W. and Seddon, J. (2015), “A cross-national environmental cluster collaboration: shifting between an analytical and management level of the triple helix", Science and Public Policy, Vol. 42 No. 4, pp. 583-593.

*Sandberg, F. and Wallo, A. (2013), "The interactive researcher as a virtual participant: a Habermasian interpretation”, Action Research, Vol. 11 No. 2, pp. 194-212.

Sandberg, J. (2000), "Understanding human competence at work: an interpretative approach", Academy of Management Journal, Vol. 43 No. 1, pp. 9-25.

Sandberg, J. and Pinnington, A.H. (2009), "Professional competence as ways of being: an existential ontological perspective", Journal of Management Studies, Vol. 46 No. 7, pp. 1138-1170.

Sannö, A. (2017), "Time to change: zipping sustainability into operations", doctoral dissertation, Mälardalen University Press, Västerås.

Seashore, S.E. (1976), "The design of action research", in Clark, A.W. (Ed.), Experimenting with Organizational Life: The Action Research Approach, Plenum Publ. Co, New York, NY, pp. 103-117.

*Seim, R., Broberg, O. and Andersen, V. (2014), "Ergonomics in design processes: the journey from ergonomist toward workspace designer", Human Factors and Ergonomics in Manufacturing, Vol. 24 No. 6, pp. 656-670.

Snoeren, M.M., Niessen, T.J.H. and Abma, T.A. (2012), "Engagement enacted. Essentials of initiating an action research project", Action Research, Vol. 10 No. 2, pp. 189-204.

*Svensson, L. (2007), "It's being close that makes it possible to accept criticism!", International Journal of Action Research, Vol. 3 No. 3, pp. 278-296.

Svensson, L. and Aagaard Nielsen, K. (2006), "A framework for the book", in Aagaard Nielsen, K. and Svensson, L. (Eds), Action and Interactive Research. Beyond Practice and Theory, Shaker Publishing, Maastricht, pp. 13-44.

Svensson, L., Brulin, G. and Ellström, P.-E... (2015), "Interactive research and ongoing evaluation as joint learning processes”, in Elg, M., Ellström, M., Klofsten, P.-E. and Tillmar, M.M. (Eds), Sustainable Development in Organizations: Studies on Innovative Practices, Edward Elgar Publishing, Cheltenham, pp. 346-361.

*Svensson, L., Ellström, P.-E. and Brulin, G. (2007), "Introduction - on interactive research", International Journal of Action Research, Vol. 3 No. 3, pp. 233-249.

*Svensson, L., Eklund, J., Randle, H. and Aronsson, G. (2007), "Interactive research-an attempt to analyse two change programmes", International Journal of Action Research, Vol. 3 No. 3, pp. 250-277.

Torraco, R.J. (2005), "Writing integrative literature reviews: guidelines and examples", Human Resource Development Review, Vol. 4 No. 3, pp. 356-367.

Torraco, R.J. (2016), "Writing integrative literature reviews: using the past and present to explore the future", Human Resource Development Review, Vol. 15 No. 4, pp. 404-428. 
Van de Ven, A.H. (2007), Engaged Scholarship: A Guide for Organizational and Social Research, Oxford University Press, Oxford.

*van der Haar, G., Heijmans, A. and Hilhorst, D. (2013), "Interactive research and the construction of knowledge in conflict-affected settings", Disasters, Vol. 37 No. 1, pp. 20-35.

Warhurst, C. and Thompson, P. (2006), "Mapping knowledge in work: proxies or practices?", Work, Employment and Society, Vol. 20 No. 4, pp. 787-800.

*Watson, T.J. (2000), "Management and interactive social science: critical participative research", Science and Public Policy, Vol. 27 No. 3, pp. 203-210.

Westlander, G. (2006), "Researcher roles in action research", in Aagaard Nielsen, K. and Svensson, L. (Eds), Action and Interactive Research. Beyond Practice and Theory, Shaker Publishing, Maastricht, pp. 45-61.

*Whitehurst, F. and Richter, P. (2018), "Engaged scholarship in small firm and entrepreneurship research: grappling with Van de Ven's diamond model in retrospect to inform future practice", International Small Business Journal: Researching Entrepreneurship, Vol. 36 No. 4, pp. 380-399.

Yorks, L. (2005), "Action research methods", in Swanson, R.A. and Holton, E. (Eds), Research in Organizations: Foundations and Methods of Inquiry, Berrett-Koehler, San Francisco, CA, pp. 375-400.

\section{Corresponding author}

Peter E. Johansson can be contacted at: peter.e.johansson@mdh.se

For instructions on how to order reprints of this article, please visit our website: 